\title{
Effect of body mass index on maternal outcome in pregnancy
}

\author{
Somya Jindal*, Rachna Chaudhary, Shakun Singh, Vandana Dhama
}

Department of Obstetrics and Gynecology, Lala Lajpat Rai Medical College, Meerut, Uttar Pradesh, India

Received: 10 March 2021

Revised: 12 April 2021

Accepted: 13 April 2021

\section{*Correspondence:}

Dr. Somya Jindal,

E-mail: somajindal@gmail.com

Copyright: (C) the author(s), publisher and licensee Medip Academy. This is an open-access article distributed under the terms of the Creative Commons Attribution Non-Commercial License, which permits unrestricted non-commercial use, distribution, and reproduction in any medium, provided the original work is properly cited.

\section{ABSTRACT}

Background: Maternal body mass index during pregnancy is one of the important parameter which gives us the clue regarding maternal complications. The objectives of this study were to study distribution of antenatal patients in underweight, normal, overweight (and obese) categories according to booking BMI, to examine the association of BMI with obstetric outcomes in singleton pregnancies.

Methods: This prospective Study was conducted over a period of 1 year from July 2019 to June 2020 on antenatal women attending OPD in the Department of Obstetrics and Gynecology in LLRM Medical College. The enrolled patients were divided into three equal groups $(n=50)$ according to their BMI. In all the groups obstetric outcome was assessed.

Results: In normal BMI group $12 \%$ patients had preterm vaginal delivery. While In group of underweight patients $32 \%$ patients landed up in preterm delivery which has three times higher incidence. In overweight group $48 \%$ patients had caesarean section, while in normal BMI group it is only $18 \%$ patients i.e. 3 times higher caesarean rate in high BMI group. $10 \%$ of patients belonging to normal BMI group needed induction of labor while $26 \%$ of patients in overweight group required induction. Thus incidence of induction of labor is more than double in overweight group. While only $16 \%$ patients had PPH in normal BMI group, $44 \%$ patients had PPH in overweight group i.e. three times higher. The frequency of preeclampsia was $22 \%$ in the overweight category and $<1 \%$ in the normal group.

Conclusions: Higher prevalence of complications to the mother when BMI is not in the recommended normal range.

Keywords: BMI, Maternal outcome

\section{INTRODUCTION}

Maternal body mass index during pregnancy is one of the important parameter which gives us the clue regarding maternal complications and fetal outcome. Routine weight measurement of pregnant women has now become accepted as one of the important tools of prenatal care in modern obstetrics, the importance of which was first enlightened by Gasser in 1962.

The women are weighed at their first antenatal visit to note the booking weight and height of the patient which is taken to calculate BMI. There is little evidence that maternal weight gain is an effective antenatal screening test for SGA infants (Gordon et al 1978; Elder et al 1979) although studies have shown a positive association between maternal BMI and infant birth weight. ${ }^{1,2}$

The women are weighed at their first antenatal visit to note the booking weight and height of the patient which is taken to calculate BMI.

The Body Mass Index (BMI) formula was developed by Belgium statistician adolphe quetelet (1796-1874) and was known as the quetelet index.

BMI is calculated the same way for both adults and children. The calculation is based on the following formulas: 


\begin{tabular}{|ll|}
\hline $\begin{array}{l}\text { Measurement } \\
\text { Units }\end{array}$ & Formula and calculation \\
\hline $\begin{array}{l}\text { Kilograms } \\
\text { and meters }\end{array}$ & weight $(\mathrm{kg}) /(\text { height }(\mathrm{m}))^{2}$ \\
\hline $\begin{array}{l}\text { Pounds and } \\
\text { inches }\end{array}$ & weight $(\mathrm{lb}) /(\text { height }(\text { in }))^{2} \times 703$ \\
\hline
\end{tabular}

The standard weight status categories associated with BMI ranges for adults are shown in the following Table.

\begin{tabular}{|l|l|}
\hline BMI & Weight status \\
\hline Below 18.5 & Underweight \\
\hline $\mathbf{1 8 . 5 - 2 4 . 9}$ & Normal \\
\hline $\mathbf{2 5 . 0 - 2 9 . 9}$ & Overweight \\
\hline $\mathbf{3 0 . 0}$ and Above & Obese \\
\hline
\end{tabular}

It is a simple useful index for evaluating pre-pregnancy nutritional status in clinical settings. In pregnancy BMI is calculated using pre-pregnancy weight. If this is unknown the first weight measurement at pre-natal care is used.

Maternal obesity adversely affects pregnancy outcome primarily through increased risks of hypertensive diseases, (chronic hypertension and pre-eclampsia) diabetes (pre-gestational and gestational), cesarean sections, infections and mal-presentation, obstetric bleeding, postpartum thrombophlebitis, UTI, dysfunctional labour, shoulder dystocia, and increased maternal morbidity due to increased operative delivery. There is also increased risk of sepsis and delayed healing of wound. ${ }^{3}$

Similarly, complications related to underweight mothers are anemia, preterm premature rupture of membrane and increased perinatal mortality ${ }^{4}$. Booking body mass index (BMI) is of clinical interest for above mentioned reasons and risk.

\section{METHODS}

This study is a prospective observational study. This Study was conducted on antenatal women attending O.P.D in the Department of Obstetrics and Gynecology in LLRM Medical College and associated SVBP Hospital, after obtaining well informed consent from the patients. The study was done over a period of 1 year from July 2019 to June 2020 .

The enrolled patients were divided into three groups according to their BMI. Equal number of patients were taken in each group for an accurate comparison. 50 patients in each group have been taken. After detailed history and examination and after fulfilling the criterion for inclusion in the study, patients were divided into 3 groups, underweight (BMI $\left.<18.5 \mathrm{~kg} / \mathrm{m}^{2}\right)-50$ patients, normal (BMI $\left.18.5-24.99 \mathrm{~kg} / \mathrm{m}^{2}\right)-50$ patients and overweight $\left(\mathrm{BMI}>25 \mathrm{~kg} / \mathrm{m}^{2}\right)-50$ patients. In all the groups maternal outcome was studied along the following lines, obstetric outcome was assessed by type of labor (spontaneous or induced), type of delivery (spontaneous vaginal, instrumental, cesarean), and period of gestation, development of PIH, anemia and postpartum hemorrhage.

These outcome variables of underweight and overweight group were compared with control group (women with normal BMI). Detailed history taking and examination was carried out with the measurement of body mass index as weight in $\mathrm{kg} /$ height in meter square.

\section{Inclusion criteria}

Pregnant mothers in $1^{\text {st }}$ trimester of pregnancy $(<14$ week). Singleton pregnancy, age 18-35 years, spontaneous conception and booked pregnant patient who will deliver in our hospital

In general we have included the pregnancy terminated prematurely, in our study, as it will help us to study the relationship of incidence of premature labour with maternal booking BMI.

The cases which have been excluded are overt diabetes, multiple pregnancy, hydramnios, intra-uterine fetal deaths.

Diabetic mothers were excluded because the disease process itself has got influence on the baby weight and thus influence the study of relationship of maternal weight gain to birth weight of baby.

For the same reason multiple pregnancy, hydramnios, still birth are excluded. Pregnant women with other systemic disorder like kidney, lung, heart, thyroid disease etc. are also excluded from the study for the same reason.

Ante-natal cases fulfilling the above mentioned criteria, coming within first trimester will be enrolled for the study after explaining them the purpose of the study. BMI will be calculated using formula: weight $/$ height $^{2}$.

Women will be classified into three groups on the basis of BMI $\left(\mathrm{kg} / \mathrm{m}^{2}\right)$, under weight (BMI $\left.\leq 19.9\right)$, normal (BMI 20-24.9) and over weight (BMI 25-29.9)and obese (BMI 30-34.9).

All women will be followed up throughout pregnancy for weight gain and any maternal complication like hypertension, diabetes and obstetrical outcome at the time of delivery in the form of type of labor (spontaneous or induced), type of delivery (spontaneous vaginal, instrumental, cesarean), period of gestation development of PIH, anemia and postpartum hemorrhage was noted in relation to BMI and was managed accordingly.

\section{Statistical analysis}

The data was entered in Microsoft Excel and appropriate statistical analysis done using statistical package for the social services (SPSS) version16.0. Proportions and 
percentages were used for categorical variables. Student $\mathrm{T}$ tests for comparison of two groups was applied for quantitative data and Chi square test for qualitative data. Results were considered to be statistically significant when $\mathrm{p}<0.05$.

\section{RESULTS}

This study includes 150 singeleton pregnant women. Equal number of patients were taken in each group for an accurate comparison 50 patient in each group had been taken. A-Under weight, B-normal weight, C-over weight and obese.

Table 1 compares the distribution of maternal BMI in age groups. $50 \%$ of patients belonging to normal BMI belonged to age group of $21-25 y$ rs, while this was $60 \%$ in overweight group and 52\% in under weight group. While $46 \%$ of patients of normal group belonged to 26-30 yrs age group this was $34 \%$ in underweight group and $32 \%$ in overweight group.

Table 1: Age distribution of mothers according to different maternal BMI groups.

\begin{tabular}{|c|c|c|c|c|c|c|}
\hline $\begin{array}{l}\text { Age Group } \\
\text { (In Years) }\end{array}$ & $\begin{array}{l}\text { Under weight } \\
(\mathbf{N}=\mathbf{5 0}) / \%\end{array}$ & $\begin{array}{l}\text { Normal } \\
(\mathbf{N}=\mathbf{5 0}) / \%\end{array}$ & $\begin{array}{l}\text { Overweight } \\
(\mathrm{N}=50) / \%\end{array}$ & Total & Chi square & P value \\
\hline$<20$ & $4 / 8 \%$ & $2 / 4 \%$ & $1 / 2.0 \%$ & $7 / 4.67 \%$ & \multirow{5}{*}{11.782} & \multirow{5}{*}{$>0.05$} \\
\hline $21-25$ & $26 / 52 \%$ & $25 / 50 \%$ & $30 / 60 \%$ & $81 / 54 \%$ & & \\
\hline 26-30 & $17 / 34 \%$ & $23 / 46 \%$ & $16 / 32 \%$ & $56 / 37.33 \%$ & & \\
\hline$>\mathbf{3 0}$ & $3 / 6 \%$ & $0 \%$ & $3 / 6 \%$ & $6 / 4 \%$ & & \\
\hline Total & $50 / 33.33 \%$ & $50 / 33.33 \%$ & $50 / 33.33 \%$ & 150 & & \\
\hline
\end{tabular}

Table 2: Mean BMI and age in different maternal BMI groups.

\begin{tabular}{|lllllll|}
\hline Parameters & Underweight & \multicolumn{3}{c}{ Normal } & Overweight \\
\hline Age & Mean & SD & Mean & SD & Mean & SD \\
\hline BMI & 25.1200 & 3.49717 & 25.5600 & 2.31376 & 25.8800 & 3.37240 \\
\hline
\end{tabular}

Table 3: Descriptive analysis according to different maternal BMI groups.

\begin{tabular}{|c|c|c|c|c|c|c|}
\hline \multicolumn{2}{|l|}{ Parameters } & $\begin{array}{l}\text { Under } \\
\text { weight } \\
(\mathrm{N}=50) / \%\end{array}$ & $\begin{array}{l}\text { Normal } \\
(\mathbf{N}=\mathbf{5 0}) / \%\end{array}$ & $\begin{array}{l}\text { Overweight } \\
(\mathrm{N}=50) / \%\end{array}$ & $\begin{array}{l}\text { Chi } \\
\text { square }\end{array}$ & $P$ value \\
\hline \multirow{2}{*}{$\begin{array}{l}\text { Socioeconomic } \\
\text { status }\end{array}$} & Lower middle class & $47 / 94 \%$ & $45 / 90 \%$ & $42 / 84 \%$ & \multirow{2}{*}{1.629} & \multirow{2}{*}{$>0.05$} \\
\hline & Upper middle class & $3 / 6 \%$ & $5 / 10 \%$ & $8 / 16 \%$ & & \\
\hline \multirow{2}{*}{ Occupation } & Housewife & $50 / 100 \%$ & $50 / 100 \%$ & $50 / 100 \%$ & \multirow[b]{2}{*}{ - } & \multirow[b]{2}{*}{ - } \\
\hline & Working & 0 & 0 & 0 & & \\
\hline \multicolumn{2}{|c|}{$\begin{array}{l}\text { Mean gestational age at booking(in } \\
\text { weeks) }\end{array}$} & $9.080 \pm 1.988$ & $8.9400 \pm 2.0$ & $9.84 \pm 2.08$ & 7.100 & $>0.05$ \\
\hline \multirow{2}{*}{$\begin{array}{l}\text { No of previous } \\
\text { ceasarean section }\end{array}$} & 0 & $44 / 88 \%$ & $40 / 80 \%$ & $42 / 84 \%$ & \multirow[t]{2}{*}{2.651} & \multirow[t]{2}{*}{$>0.05$} \\
\hline & 1 & $6 / 12 \%$ & $10 / 20 \%$ & $8 / 16 \%$ & & \\
\hline \multirow{2}{*}{ BP } & Systolic & $117.400 \pm 5.7$ & $118.4 \pm 5.54$ & $12.80 \pm 11.44$ & \multirow[b]{2}{*}{9.051} & \multirow{2}{*}{$<0.05$} \\
\hline & Diastolic & $78.320 \pm 5.69$ & $78.9 \pm 4.646$ & $86.20 \pm 7.013$ & & \\
\hline \multicolumn{2}{|c|}{ Fundal height at term pregnancy } & $35.36 \pm 1.687$ & $37.12 \pm 1.40$ & $37.96 \pm 1.689$ & 3.917 & $<0.05$ \\
\hline \multirow{2}{*}{ Hemoglobin } & $\mathrm{Hb}($ in $\mathrm{gm} * \mathrm{dl})<10$ & $42 / 84 \%$ & $38 / 76 \%$ & $39 / 78 \%$ & \multirow[b]{2}{*}{2.186} & \multirow{2}{*}{$<0.05$} \\
\hline & $\mathrm{Hb}($ in $\mathrm{gm} * \mathrm{dl})>10$ & $8 / 16 \%$ & $12 / 24 \%$ & $13 / 26 \%$ & & \\
\hline \multirow{3}{*}{$\begin{array}{l}\text { Amniotic fluid } \\
\text { index }\end{array}$} & $\begin{array}{l}\text { Oligohydramnios } \\
\text { AFI }<5\end{array}$ & $2 / 4 \%$ & $1 / 2.0 \%$ & $2 / 4.0 \%$ & \multirow{3}{*}{10.172} & \multirow{3}{*}{$>0.05$} \\
\hline & Normal 5-24 & $48 / 96 \%$ & $49 / 98 \%$ & $48 / 96 \%$ & & \\
\hline & $\begin{array}{l}\text { Polyhydramnios } \\
\text { AFI> } 24\end{array}$ & 0 & 0 & 0 & & \\
\hline \multicolumn{2}{|l|}{ Mean RBS } & $78.96 \pm 5.469$ & $78.36 \pm 5.33$ & $85.78 \pm 7.33$ & 5.19 & $>0.05$ \\
\hline \multicolumn{2}{|c|}{ Fetal weight on USG } & $2.548 \pm 0.406$ & $2.83 \pm 0.393$ & $2.97 \pm 0.408$ & 3.188 & $>0.05$ \\
\hline
\end{tabular}


While $0 \%$ of patients of normal group were above 30yrs of age this was $6 \%$ in overweight group. When different age groups were compared for distribution of BMI, $\mathrm{p}$ value came out to be $>0.05$ making it statistically insignificant.

Table 2 describes about the minimum and maximum BMI in the study population which was $18.06 \mathrm{~kg} / \mathrm{m}^{2}$ and 26.45 $\mathrm{kg} / \mathrm{m}^{2}$ respectively. The mean BMI of whole study group came out to be $22.74 \mathrm{~kg} / \mathrm{m}^{2}$ with standard deviation of 33 .

Study population was divided into three groups on the basis of BMI, underweight $\left(\mathrm{BMI}<18.5 \mathrm{Kg} / \mathrm{m}^{2}\right)$, normal (BMI $\left.18.5-24.99 \mathrm{Kg} / \mathrm{m}^{2}\right)$, overweight $\left(25 \mathrm{Kg} / \mathrm{m}^{2}\right.$ and above).

Table 3 shows descriptive analysis of various parameters in different BMI groups.

Table 4 shows that none in normal group and none in underweight group developed PIH, 11 patients i.e. $22 \%$ in overweight group developed PIH. The result came out to be statistically significant with $\mathrm{p}$ value of $<0.05$.

Table 4: Frequency of PIH in different maternal BMI groups.

\begin{tabular}{|llll|}
\hline BMI & PIH & & Total \\
\hline Underweight & Absent & Present & \\
\hline Normal & $50 / 100 \%$ & 0 & 50 \\
\hline Overweight & $39 / 780 \%$ & 0 & 50 \\
\hline Total & $139 / 92.66 \%$ & $11 / 22 \%$ & 50 \\
\hline Chi square & 12.714 & & 150 \\
\hline P value & $<0.05$ & & \\
\hline
\end{tabular}

Table 5: Mode of delivery in different maternal BMI groups.

\begin{tabular}{|lllll|}
\hline \multirow{2}{*}{ Groups } & Mode of delivery & & \multirow{2}{*}{ Total } \\
\cline { 2 - 5 } Underweight & FTVD & LSCS & PTVD & \\
\hline Normal & $35 / 50 \%$ & $9 / 18 \%$ & $16 / 32 \%$ & 50 \\
\hline Overweight & $24 / 48 \%$ & $9 / 18 \%$ & $6 / 12 \%$ & 50 \\
\hline Total & $84 / 56 \%$ & $42 / 28 \%$ & $24 / 16 \%$ & 50 \\
\hline Chi square & 10.230 & & & \\
\hline p value & $<0.05$ & & & \\
\hline
\end{tabular}

Table 5 describes that of 50 patients with normal BMI, 35 patients had full term normal vaginal delivery 9 had undergone caesarean section while 6 patients had preterm vaginal delivery. In group of underweight patients 25 had full term vaginal delivery 9 had caesarean section while 16 patients landed up in preterm delivery.

In overweight group 24 patients had normal delivery and 24 patients had caesarean section. Two patients in this group had preterm delivery. $\mathrm{P}$ value is 0.00 which is statistically significant (less than 0.05).

Table 6: Anemia in different maternal BMI groups.

\begin{tabular}{|llll|}
\hline Groups & $\begin{array}{l}\text { Anemia } \\
\text { Present }\end{array}$ & Absent & Total \\
\hline Underweight & $42 / 84 \%$ & $8 / 16 \%$ & 50 \\
\hline Normal & $38 / 76 \%$ & $12 / 24 \%$ & 50 \\
\hline Overweight & $37 / 74 \%$ & $13 / 26 \%$ & 50 \\
\hline Total & $117 / 78 \%$ & $33 / 22 \%$ & 150 \\
\hline Chi square & 9.209 & & \\
\hline P value & $<0.05$ & & \\
\hline
\end{tabular}

Table 6 depicts the prevalence of anemia in study group. Out of 50 underweight about $42(84 \%)$ are anemic while in normal and underweight about $75 \%$ are anemic so $\mathrm{p}$ value came out to be $<0.05$ so it is statistically significant.

Table 7: Need for induction of labour in different maternal BMI groups.

\begin{tabular}{|c|c|c|c|}
\hline \multirow{2}{*}{ Groups } & \multicolumn{2}{|c|}{ Need for induction } & \multirow{2}{*}{ Tota } \\
\hline & No & Yes & \\
\hline Underweight & $46 / 92 \%$ & $4 / 8 \%$ & 50 \\
\hline Normal & $45 / 90 \%$ & $5 / 10 \%$ & 50 \\
\hline Overweight & $37 / 74 \%$ & $13 / 26 \%$ & 50 \\
\hline Total & $128 / 85.33 \%$ & $22 / 14.67 \%$ & 150 \\
\hline Chi square & 1.457 & & \\
\hline P value & $<0.05$ & & \\
\hline
\end{tabular}

Table 7 shows that 5 of 50 patients belonging to normal BMI group needed induction of labour due to various reasons like post-dated pregnancy, premature rupture of membranes, preeclampsia, while 13 patients of 50 patients in overweight group required induction. 4 of the patients in underweight group required induction. This depicts that in overweight group around $26 \%$ need induction which $\mathrm{p}$ value came out to be $<0.05$ hence it is statistically significant.

Table 8: Frequency of post-partum hemorrhage in various maternal BMI groups.

\begin{tabular}{|llll|}
\hline Groups & \multicolumn{2}{l}{ Postpartum hemorrhage } & Total \\
& No & Yes & \\
\hline Underweight & $49 / 98 \%$ & $1 / 2.0 \%$ & 50 \\
\hline Normal & $42 / 84 \%$ & $8 / 16 \%$ & 50 \\
\hline Overweight & $28 / 56 \%$ & $22 / 44 \%$ & 50 \\
\hline Total & $119 / 79.33 \%$ & $31 / 20.67 \%$ & 150 \\
\hline Chi square & 2.934 & & \\
\hline P value & $<0.05$ & & \\
\hline
\end{tabular}

Table 8 describes the frequency of post-partum hemorrhage in various BMI groups. While only 16 patients had PPH in normal BMI group, a ratio of almost $50 \%$ i.e. 22 patients had PPH of various degrees (mild \& moderate) in overweight group. $\mathrm{PPH}$ is both after 
cesarean and normal deliveries but in overweight pt it is more after cesarean deliveries and mostly of mild to moderate degree only 2 out of 22 in this group went into severe degree of PPH. Two\% of the patients belonging to underweight group underwent $\mathrm{PPH}$ which is of mild degree and after vaginal deliveries. PPH in all the groups was managed conservatively and none of them required surgical management. This is statistically significant as $\mathrm{p}$ value is $0.0(<0.05)$.

Table 9: Maternal outcome in different maternal BMI groups.

\begin{tabular}{|c|c|c|c|c|c|c|c|}
\hline \multirow{2}{*}{\multicolumn{2}{|c|}{ Parameters }} & \multicolumn{2}{|c|}{ Underweight } & \multicolumn{2}{|c|}{ Normal } & \multicolumn{2}{|c|}{ Overweight } \\
\hline & & $\mathbf{N}=\mathbf{5 0}$ & $\%$ & $\mathrm{~N}=\mathbf{5 0}$ & $\%$ & $\mathbf{N}=\mathbf{5 0}$ & $\%$ \\
\hline \multicolumn{2}{|c|}{ Preterm labour } & 16 & 32 & 6 & 12 & 2 & 4 \\
\hline \multirow{3}{*}{$\begin{array}{l}\text { Mode Of } \\
\text { Delivery }\end{array}$} & LSCS & 9 & 18 & 9 & 18 & 24 & 48 \\
\hline & FTVD & 25 & 50 & 35 & 70 & 24 & 48 \\
\hline & PTVD & 16 & 32 & 6 & 12 & 2 & 4 \\
\hline \multicolumn{2}{|c|}{ Induced labour } & 4 & 8 & 5 & 10 & 13 & 26 \\
\hline \multicolumn{2}{|c|}{ PPH } & 1 & 2 & 8 & 16 & 22 & 44 \\
\hline \multirow[b]{2}{*}{ Hemoglobin } & $\mathrm{Hb}\left(\right.$ in $\left.\mathrm{gm}^{*} \mathrm{dl}\right)<10$ & 42 & 84 & 38 & 76 & 39 & 78 \\
\hline & $\mathrm{Hb}\left(\right.$ in $\left.\mathrm{gm}^{*} \mathrm{dl}\right)>10$ & 8 & 16 & 12 & 24 & 13 & 26 \\
\hline \multirow{2}{*}{ PIH } & PRESENT & 0 & 0 & 0 & 0 & 11 & 22 \\
\hline & ABSENT & 50 & 100 & 50 & 100 & 39 & 78 \\
\hline \multirow{3}{*}{$\begin{array}{l}\text { Amniotic } \\
\text { Fluid Index }\end{array}$} & Oligohydramnios AFI $<5$ & 2 & 4 & 1 & 2 & 2 & 4 \\
\hline & Normal 5-24 & 48 & 96 & 49 & 98 & 48 & 96 \\
\hline & Polyhydramnios AFI $>24$ & 0 & 0 & 0 & 0 & 0 & 0 \\
\hline \multicolumn{2}{|c|}{ Total weight gain (in kg) } & \multicolumn{2}{|l|}{8.166} & \multicolumn{2}{|l|}{8.86} & \multicolumn{2}{|l|}{10.17} \\
\hline
\end{tabular}

Table 10: Gest diabetes>126 and BMI.

\begin{tabular}{|lccc|}
\hline Parameters & $\begin{array}{l}\text { Under } \\
\text { Weight }\end{array}$ & Normal & Overweight \\
\hline $\begin{array}{l}\text { Mean BMI in } \\
\text { RBS }>\text { 126 }\end{array}$ & 0 & 0 & 0 \\
\hline
\end{tabular}

Table 9 compiles all the maternal outcome in different BMI groups.

\section{DISCUSSION}

Obesity has become an epidemic worldwide. WHO has declared obesity as a major killer disease of the millennium at par with malnutrition and HIV. The antenatal, intrapartum, postpartum and neonatal assessment was done and outcome of each pregnancy in terms of maternal morbidity and mortality were studied.

\section{Weight gain during pregnancy}

The mean gestational weight gain in women who were underweight was $8.166 \mathrm{~kg}$, whereas it was $8.86 \mathrm{~kg}$ in normal BMI group and $10.17 \mathrm{~kg}$ in overweight group. Mollar ex al have shown that in African women total pregnancy weight gain is of $6 \mathrm{~kg}^{5}$ Mean weight gain during pregnancy in India is only about $6 \mathrm{~kg}$ (Anderson MA. Relationship between maternal nutrition and child growth in rural India. Doctoral thesis Tufts University 1989, p 159, unpublished). Addo $\mathrm{V} \mathrm{N}$ also found a statistically significant high total weight gain $(>16 \mathrm{~kg})$ in overweight and obese patients as compared to normal BMI patients. ${ }^{6}$

\section{Antepartum complications}

Pregnancy induced hypertension

In our study, the frequency of preeclampsia remained significantly high in overweight category as compared to normal and underweight groups. The frequency of preeclampsia was $22 \%$ in the overweight category and $<1 \%$ in the normal category.

The difference was statistically significant with a $\mathrm{p}$ value of <0.05. Eclampsia was not found in any category. Results were comparable with Voigt et al (2008) who found that $37.9 \%$ patients in the BMI $>30$ category had preeclampsiaand $1.2 \%$ in the $\mathrm{BMI}<25$ category had preeclampsia. ${ }^{7}$ Ehrenthal DB (2011) also concluded that preeclampsia was more common in the obese with a $\mathrm{p}$ value of less than 0.0001. Also, Baeten JM et al found that incidence of eclampsia increased with increasing BMI. ${ }^{8,9}$

\section{Gestational diabetes mellitus}

Results of our study show that none of the patients in whole study group had gestational diabetes mellitus .Our results were similar to the study by Kongubol A and 
Phupong V (2011) who said that pre-pregnancy obesity without metabolic problems did not increase the risk for GDM. The risk of Diabetes Mellitus increases as the age increases, especially after 45 years of age. As our study group was of a younger age group, rates of diabetes could not be calculated. ${ }^{10}$

\section{Anemia}

Prevalence of anemia in normal group was 76\%, 74\% in the overweight category and $84 \%$ in underweight group. The difference was statistically significant with a $p$ value of <0.05. These results could be due to possible nutritional etiology of anemia in the population. The results were consistent with Sahu et al (2007) who concluded that anemia (\#=0.02) was significantly present among lean women. ${ }^{11}$

\section{Amniotic fluid index on USG}

Oligohydramnios in the normal BMI category was $2 \%$ and in the overweight category was $4 \%$ and these were also $4 \%$ in the underweight category. The difference in ultrasound findings remained statistically insignificant with a $p$ value of 0.56 .

\section{Preterm labor}

Preterm labor pains occurred in $12 \%$ of the pregnancies with normal BMI, $32 \%$ in the low BMI and $4 \%$ in overweight group. The difference was statistically significant with a $\mathrm{p}$ value of 0.00 . The study was similar to a study by Hendler et al who stated that obese women had fewer spontaneous preterm births at $<37$ weeks of gestation $(6.2 \%$ vs $11.2 \%$; $\#<001)$ and at $<34$ weeks of gestation $\left(1.5 \%\right.$ vs $3.5 \%$; \# =012). ${ }^{12}$

Women with a body mass index of $<19 \mathrm{~kg} / \mathrm{m}^{\prime}$ had $18 \%$ spontaneous preterm birth, with a body mass index of 19 to $24.9 \mathrm{~kg} / \mathrm{m}$ had $8 \%$ spontaneous preterm birth, with a body mass index of 25 to $29.9 \mathrm{~kg} / \mathrm{m}$ had $0 \%$ spontaneous preterm birth, Hence, when controlling for confounders, obesity and morbid obesity were not associated with prematurity. Similar results were reported by Ehrenberg et al (2003) who concluded that low weight and BMI at conception or delivery, as well as poor weight gain during pregnancy, are associated with LBW, prematurity, and maternal delivery complicationspatients. ${ }^{13}$

\section{Intrapartum complications}

\section{Mode of delivery}

Results of this study show significantly higher rates of cesarean section in overweight group as compared to normal and underweight group) (48\% versus $18 \%$ and $18 \%$ respectively). The results could be compared with those of Pevzner L et al (2009) who said that the incidence of cesarean delivery increased from $21.3 \%$ in the BMI less than 30 group to $29.8 \%$ in the BMI $30-39{ }^{9}$ group and $36.5 \%$ in the BMI 40 or higher group. ${ }^{14}$ Also, Kominiarek MA et al (2010) said that the risk for cesarean increased as BMI increased for all subgroups, $\mathrm{P}<.001 .^{15}$

The results were inconsistent with that of Bhattacharya et al (2007), who reported $41.5 \%$ emergency LSCS in the normal and $58.8 \%$ in the obese group. ${ }^{16}$

The cesarean section rate increased, along with maternal BMI, in most studies including the present one $(\mathrm{P}=$ 0.01). The higher cesarean section rate in obese women carries an extra risk of higher perioperative morbidity, including anesthetic problems, infections, blood loss and prolonged hospitalization.

Reasons reported for surgery generally include macrosomia-associated cephalo-pelvic disproportion, fetal distress and stagnation of induced labor. Most common reason for caesarean sections in BMI $>25$ group was preeclampsia with/without IUGR/Doppler abnormalities. Most common reason for caesarean sections in $\mathrm{BMI}<25$ group was Meconium stained liquor intra-partum.

\section{Need for induction}

Inductions were done in $10 \%$ of the normal BMI group and $26 \%$ of the overweight group whereas in $8 \%$ of the patients of underweight group. The difference was statistically significant with a $\mathrm{p}$ value of $<0.05$. The most common indication for induction in the overweight group was preeclampsia, whereas premature rupture of membranes was the most common indication in normal group.

Our results were comparable with Jensen DM et al (2003) They reported that the risk of induction of labor was significantly increased in both overweight women (body mass index (BMI) $25.0-29.9 \mathrm{~kg} / \mathrm{m}$ ) and obese women (BMI $30.0 \mathrm{~kg} / \mathrm{m}^{\prime}$ ) compared with women who were of normal weight (BMI 18.5-24.9 kg/m'). ${ }^{17}$

Also, Elíasdóttir ÓJ et al (2010) who reported that obese women have a significantly increased risk of requiring induction of labor compared with normal weight women. ${ }^{18}$

\section{Postpartum complications}

\section{Postpartum hemorrhage (PPH)}

PPH occurred in $16 \%$ of the patients in normal BMI group and in $44 \%$ of the patients in the overweight category. The difference was statistically significant with a $\mathrm{p}$ value of 0.00 . The results were in corroboration with Bhatthacharya et al (2005) who quoted that obese women were more likely to have postpartum hemorrhage (OR 1.5 $95 \%$ CI $1.3,1.7){ }^{16}$ 
Our results were also consistent with those of T.S. UshaKiran, et al (2005) who reported an increased risk (quoted as odds ratio (OR) and confidence intervals $\mathrm{CI}$ ) of maternal complications such as blood loss of more than $500 \mathrm{ml}$, amounting to postpartum hemorrhage in obese women. ${ }^{19}$

Limitation: The present study had several limitation, the sample size was small therefore statistical power of the study was low; but this was due to it being a prospective study carried out in one unit of a tertiary care teaching hospital over a period of 1 year only, with many exclusion criteria.

Also COVID-19 pandemic and subsequent lockdown and shutdown of OPD services led to decrease in sample size which was originally planned as 100 cases in each group. The sample was not homogeneous with regard to age, education and socio- economic status. All these factors may impact quality of life and BMI and, hence, the study results. Study did not distinguish between women who were thin but healthy and women who were underweight because they were ill.

\section{CONCLUSION}

From this study it may be concluded that with proper management of pregnant women with a higher BMI, improvement in awareness amongst the women and increasing their accessibility to medical facilities, maternal and perinatal morbidity and mortality can be minimized. Higher prevalence of complications to both the fetus and the mother when BMI is not in the recommended normal range.

Therefore, it is a must for all pregnant and non-pregnant women to be aware of the maternal complications arising due to inappropriate Body Mass Index. Both lean and obese mothers carry an increased risk of adverse maternal outcome.

\section{ACKNOWLEDGMENTS}

We would like to thank Dr. Devanshu Mohaniya for providing us useful information and constant encouragement.

\section{Funding: No funding sources}

Conflict of interest: None declared

Ethical approval: The study was approved by the Institutional Ethics Committee

\section{REFERENCES}

1. Gordon YB, Lewis JD, Pendlebury DJ, Leighton M, Gold J. Is measurement of placental function and maternal weight worthwhile. Lancet. 1978;311(8072):1001-3.

2. Elder MG, Burton ER, Gordon H, Hawkins DF, McClure Browne JC. Maternal weight and girth changes in late pregnancy and the diagnosis of placental insufficiency. J. Obstet Gynecol Br. Commorth. 1970;77(6):481-91.

3. Allen L.H. et. Maternal body mass index and pregnancy outcome. Eur J Clin Nutr. 1994;48(3):568-77.

4. Spy ZM, et al. Outcome of Pregnancy in underweight women after spontaneous and induced ovulation, Br. Med. J. 1988;296(6627):962-3.

5. Moller B, Gebre-Medhin M, LindmarkG. Maternal weight, weight gain and termin the rural Tanzanian village of Hula. $\mathrm{Br} \mathbf{J}$ Obstet Gynecol. 1989;96(2):158-66.

6. Addo VN. Body mass index, weight gain during pregnancy and obstetric outcomes. Ghana Med J. 2010;44(2):64-8.

7. Voigt M, Straube S, Zygmunt M, Krafczyk B, Schneider KT, Briese. Obesity and pregnancy a risk profile. Z Geburtshilfe Neonatol. 2008;212(6):201-5.

8. Ehrenthal DB, Jurkovitz C, Hoffman M, Jiang X, Weintraub WS. P repregnancy body mass index as an independent risk factor for pregnancy- induced hypertension. J Womens Health (Larchmt). 2011;20(1):67-72.

9. Baeten JM, Bukusi EA, Lambe M. Pregnancy complications and outcomes among overweight and obese nulliparous women. Am J Public Health. 2001;91(3):436-40.

10. Kongubol A, Phupong V. Prepregnancy obesity and the risk of gestational diabetes mellitus. BMC Pregnancy Childbirth. 2011;11(1):59.

11. Sahu, Meenakshi T., Anjoo Agarwal, Vinita Das, and Amita Pandey. "Impact of maternal body mass index on obstetric outcome." J Obstet and Gynaec Res. 2007;33(5):655-9.

12. Hendler I, Goldenberg RL, Mercer BM, Iams JD, Meis PJ, Moawad AH, MacPherson CA, Caritis SN, Miodovnik M, Menard KM, Thurnau GR, Sorokin Y. The Preterm Prediction Study: association between maternal body mass index and spontaneous and indicated preterm birth. Am J Obstet Gynecol. 2005 Mar;192(3):882-6. doi: 10.1016/j.ajog.2004.09.021. PMID: 15746686.

13. Ehrenberg HM, Dierker L, Milluzzi C, Mercer BM. Low maternal weight, failure to thrive in pregnancy, and adverse pregnancy outcomes. Am J Obstet Gynecol. 2003 Dec;189(6):1726-30. doi: 10.1016/s0002-9378(03)00860-3. PMID: 14710105.

14. Pevzner L, Powers BL, Rayburn WF, Rumney P, Wing DA. Effects of maternal obesity on duration and outcomes of prostaglandin cervical ripening and labor induction. Obstet Gynecol. 2009;114(6):131521.

15. Kominiarek MA, Vanveldhuisen P, Hibbard J, Landy $\mathrm{H}$, Haberman S, Learman L et al. The maternal body mass index: a strong association with delivery route. Am J Obs \& Gyn.e 2010;203(3):264.e1-264.e7.

16. Bhattacharya S, Campbell DM, Listion WA, Bhattacharya S: Effect of body Mass index On Pregnancy outcomes in Nulliparous women 
delivering singleton babies. BMC public Health. 2007;7(1):168.

17. Jensen DM, Ovesen P, Beck-Nielsen H, MalstedPedersen L, Sarensen B, Vintercetal. Gestational weight gain and pregnancy outcomes in 481obese glucose-tolerant women. Diabetes Care. 2005;28(9):2118-2122b.

18. Elíasdóttir ÓJ, Haròardóttir H, bórkelsson. The effect of maternal weight on pregnancy outcome. Laeknabladid. 2010;96(11):691-6.
19. UshaKiran TS, Hemmadi S, Bethel J, Evans J. Outcome of pregnancy in a woman with an increased body mass index. BJOG. 2005;112(6):768-772.

Cite this article as: Jindal S, Chaudhary R, Singh S, Dhama V. Effect of body mass index on maternal outcome in pregnancy. Int J Reprod Contracept Obstet Gynecol 2021;10:1983-90. 